\title{
Intelligent Logistics Distribution System Design under the Environment of Internet of Things
}

\author{
Yun WU $\mathbf{W}^{1, \mathrm{a}}$ \\ ${ }^{1}$ HLILONGJIANG UNIWERSITY OF TECHNOLOGY, Jixi 158100, China \\ a Bjsy_1006@163.com
}

Keywords: Internet of Things; Intelligent logistics; Distribution System

\begin{abstract}
With the proposed concept of things, things technology in logistics and distribution will promote the further development of logistics and distribution. Based on the current status of domestic and international distribution logistics comparative study found insufficient logistics existing in our country at present, proposed application of networking technology to solve these problems, all aspects of logistics and distribution needs of networking technology for the analysis, with Things technology integration means to optimize the distribution process, on this basis, build a distribution system for the design of the system architecture and functionality, and the establishment of a logistics optimization model provides theoretical support for scientific and effective decision-making system . Through this study, we can promote networking technology in logistics and distribution, improve logistics and distribution mechanization, intelligent, level of information, to provide a reference for the development of China's logistics industry.
\end{abstract}

\section{Introduction}

Intelligent enterprise supply chain logistics is an integral part, it is to meet the customer needs to goods, services and related information from the origin to point of consumption as well as cost-effective for storage functions liquidity planning, implementation and effective control of the process. Enterprise logistics information, it is adapted to the requirements of economic globalization and market integration, full use of modern means of information, the logistics market to make quick response to rapid and effective integration of resources, and logistics, capital flow and information flow Optimal integrated management model and innovative models. Through the logistics information technology, can speed up the realization of their own benefit. Warehouse as a corporate store supplies and turnover of places, and so was the backlog of area and working area of enterprise funds [1-2]. Reduce inventory levels to reduce costs has a very important role, but for various reasons are often received little importance in enterprises. While noting that some companies that should reduce inventory, speed up the turnover of materials, but do not know how to reduce inventory [3].

Things technology is an important part of a new generation of information technology, the Internet by means of a new technology in the form of sensing technology by the virtual reality space to expand the physical space, but also the countries trying to seize the information technology revolution of the growing point. It aims to achieve the goods efficient, accurate, safe, green management, control and operation of the integrated operation. Things technology applications in the logistics field to subvert and transform the traditional logistics industry and logistics management, modern logistics provides a strong technical support and distribution. In the near future, things are bound to the theory and technology deep into all aspects of the logistics field.

\section{Concept of Internet of things}

Internet of things is a multidisciplinary highly cross emerging frontier research focus in the field, it combines sensor technology, embedded computing technology, modern network and wireless communication technology, distributed information processing technology, etc., through all kinds of integrated micro sensor collaboration to real-time monitor, sense and collect all kinds of 
environmental or monitoring object information, through the embedded system in information processing, and through random self-organizing wireless network with multiple hops relaying mode will be perceived information transmitted to the user terminal [4-5]. In architecture, the architecture of Internet of things technology mainly includes the perception layer, network layer, application layer, as shown in figure 1.

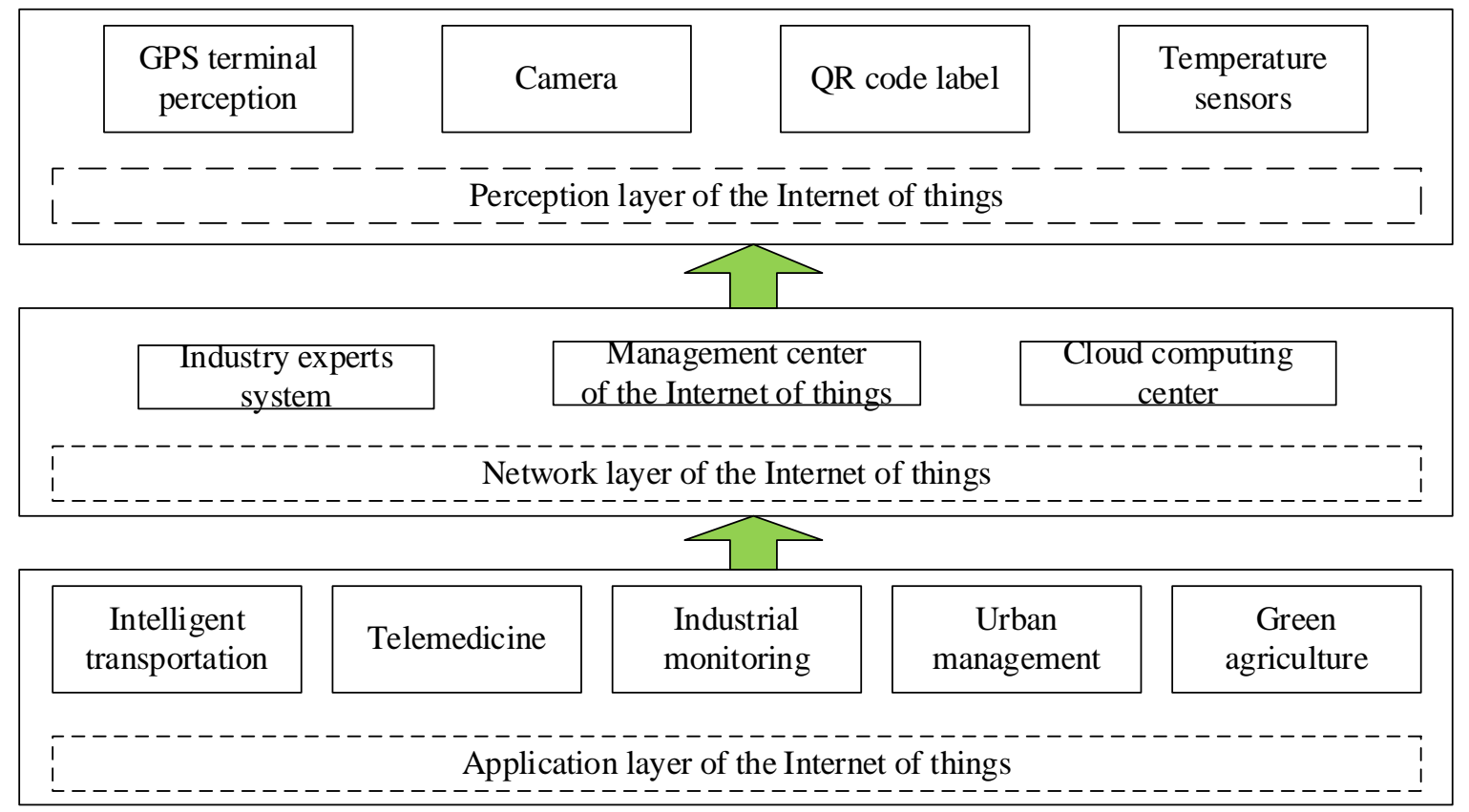

Figure 1.Technology architecture of Internet of things

Perception layer. The real-world perception layer in a wide range of various physical quantities through a variety of means, and automated real-time digital information into the virtual world can handle. Perception layer is the foundation of things, the main achievement of the IntelliSense features, including information gathering, object recognition and other functions. The main perception layer application techniques include sensor, self-organizing network, two-dimensional code and real-time location technology.

Network layer. The network layer are transmitted and processed communication of information, the perception layer collected data and information quickly and safely delivered to the information demand side to facilitate their information processing, the main means of transmission, including wireless communication and wired communications.

Application layer. The application layer of the final integration of things and all walks of life, will preclude the collection after sensing data and network layers of processing applications that require the industry, for the final system integration, coordination, decision-making and intelligence service.

The most common is the RFID technology, which not only can store a huge amount of information, but also to read the information at a very fast moving objects environment, and a number of RFID tags can be read at the same time, more than the original barcode technology convenience and operability, been widely used in warehouse operations, etc., can effectively relieve cargo handling, scan code and other activities. If the supplier of the goods are supplied RFID tags placed on cargo container or chassis, with the harvesting and sorting in storage, a library during the RFID technology can be used directly for the goods out of storage register, inventory and warehouse real-time monitoring and so on; remote data transmission technology is mainly based on wireless transmission (GPRS and CDMA) and cable transmission (PON and DSL) two ways, is different in two ways; information intelligent processing and control technology refers to read and transferred vast amounts of information storage, analysis and post-processing analysis, and the results processed back to the things of the control system, the link between things. 


\section{Supply chain management business process design based networking technology}

Things in the enterprise application, you can enhance supply chain visibility, improve the transparency of information supply chain management, improve resource utilization, reduce operating costs, improve the ability to respond to the market to meet customer demand for personalized. Use networking technology can improve supply chain works [6].

IT and continuous development of things, supply chain management systems are widely used in the global enterprise. Supply chain management, is to meet at a certain level of service, in order to make the system cost and the use of the smallest suppliers, manufacturers, wholesalers and retailers to effectively combine into one to produce goods, and the correct number of goods at the right time delivery to the correct way locations. The core idea of supply chain management system is integrated, systematic, by changing the way information is passed on to these related businesses to integrate resources of mutual cooperation, to achieve efficient operational efficiency. Supply chain management system is based on networking technology from things related to technology, computer hardware and software technology, and professional management model, as shown in Fig.

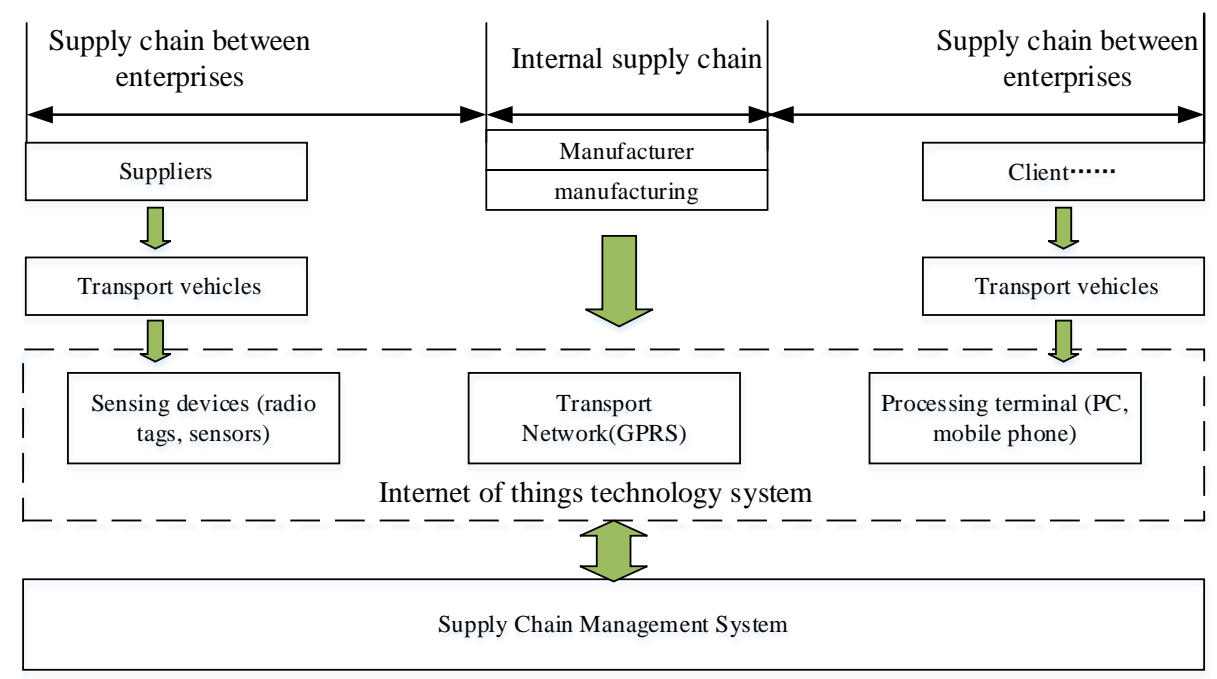

Figure 2. Business process of supply chain management model based on Internet of things

\section{Intelligent logistics system design based on Internet of things}

A current IOT technology has begun to be widely used in logistics and distribution industries, however, networking applications in the logistics industry is still relatively junior, more local, less intelligent. Many of our logistics and distribution companies are just implement networking technology in the logistics and distribution in a certain part of the application, such as product traceability in distribution centers and widely used technology for handheld terminal applications in the distribution process, but these are far from far enough, to achieve better and faster development of logistics and distribution, the establishment of a more perfect modern logistics industry, also need uniform standards, to establish a unified networking platform, to achieve interoperability, convergence, the need for more extensive coverage, needs more in-depth comprehensive perception, need more wisdom applies networking technology integrated logistics needs emerging field of logistics innovation networking application mode. In this paper, following on Internet of Things technology in logistics and distribution in the functional integration of design, through the establishment of distribution system approach to achieve intelligent logistics and distribution processes, information technology and automation. Design as shown in Figure 3 overall distribution system architecture based networking technology. 


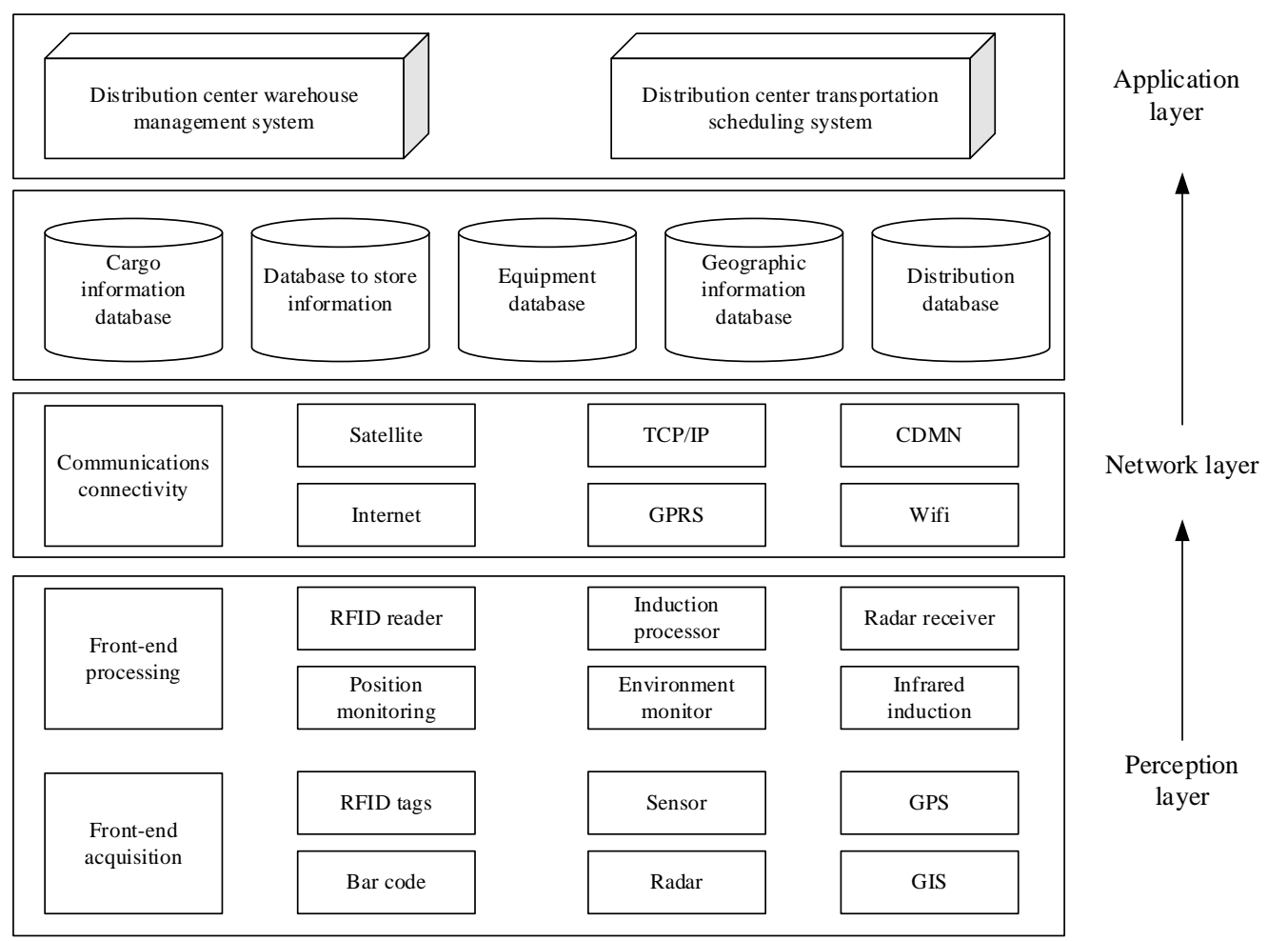

Figure 3. Intelligent logistics system design based on Internet of things

Logistics and distribution system architecture perception layer include information collection and information processing in two parts. Information collection is the use of a variety of sensor technology, microwave technology, video technology and other networking information set technology, combined with radio frequency technology, vehicle identification systems, global positioning systems and wireless communications systems and other in-transit vehicle detection technology, logistics and distribution center and distribution centers to the delivery of goods during node information collection, delivery vehicles and personnel scheduling control. The transport layer is mainly composed of common mobile communication network, the Internet, satellite communications network to achieve the transmission of information. Warehouse management system mainly intelligent logistics distribution center inside the various operations, mechanization and automation. Transport scheduling system is mainly to achieve real-time vehicle location, transport article surveillance, online scheduling and distribution visualization. Logistics and distribution system to ensure efficient, safe, accurate and need to get a lot of information, including cargo information, storage information, vehicle information, route information.

\section{Conclusion}

In the era of things, through the information system will be connected to the network electronic tag logistics enterprises and wireless sensing equipment components, the use of global positioning systems, geographic information systems and information analysis technology, logistics and competitiveness of enterprises will have a huge impact. After making the logistics and distribution system of things has been a fundamental change in the existing management and information system architecture must be major changes, through data mining and processing more intelligent, eliminating the standard questions, such as the Internet of Things, breakthrough bottleneck in the development of things. Intelligent development will require a more complex information system, which must be the development trend of things information systems, logistics and distribution system throughout the entire process, making it more and more based on value-added information efficiently and accurately. Based on the following development in logistics RFID, GIS and other new technologies, management will continue to innovate, reduce logistics process of human error, and gradually reduce labor costs and improve the efficiency of logistics and distribution system, in 
achieving the goal of intelligent distribution system under the premise, more exploration and practice.

\section{Reference}

[1] Gubbi J, Buyya R, Marusic S, et al. Internet of Things (IoT): A vision, architectural elements, and future directions[J]. Future Generation Computer Systems, 2013, 29(7): 1645-1660.

[2] Atzori L, Iera A, Morabito G. The internet of things: A survey[J]. Computer networks, 2010, 54(15): 2787-2805.

[3] Baoyun W. Review on internet of things[J]. Journal of Electronic Measurement and Instrument, 2009, 23(12): 1-7.

[4] Mattern F, Floerkemeier C. From the Internet of Computers to the Internet of Things[M]//From active data management to event-based systems and more. Springer Berlin Heidelberg, 2010: 242-259.

[5] Vermesan O, Friess P, Guillemin P, et al. Internet of things strategic research roadmap[J]. O. Vermesan, P. Friess, P. Guillemin, S. Gusmeroli, H. Sundmaeker, A. Bassi, et al., Internet of Things: Global Technological and Societal Trends, 2011, 1: 9-52.

[6] Kiritsis D. Closed-loop PLM for intelligent products in the era of the Internet of things[J]. Computer-Aided Design, 2011, 43(5): 479-501. 